\title{
(Des)orden nacional: la construcción de la migración venezolana como una amenaza de salud y seguridad pública en Colombia
}

\author{
National Dis(order): The Construction of \\ Venezuelan Migration as a Public Health and \\ Security Threat in Colombia
}

(Des)ordem nacional: a construção da migração venezuelana como uma ameaça de saúde e segurança pública na Colômbia

Juan Thomas Ordóñez, PhD¹*;

Hugo Eduardo Ramírez Arcos, $\mathrm{PhD}^{2}$

Recibido: 10 de junio de 2018 - Aceptado: 20 de septiembre de 2018

Doi: http://dx.doi.org/10.12804/revistas.urosario.edu.co/revsalud/a.8119

Para citar este artículo: Ordóñez JT, Ramírez-Arcos HE. (Des)orden nacional: la construcción de la migración venezolana como una amenaza de salud y seguridad pública en Colombia. Rev Cienc Salud. 2019;17(especial):48-68. Doi: http://dx.doi.org/10.12804/revistas. urosario.edu.co/revsalud/a.8119

\section{Resumen}

Introducción: en este artículo se propone una reflexión sobre la construcción mediática y política de la imagen del migrante venezolano como amenaza a la salud y seguridad pública en Colombia. Desarrollo: a partir de 2015, la migración masiva de venezolanos enfrenta a la sociedad colombiana a una situación inédita en su historia reciente. En medio de un contexto atravesado por la hiperpolitización de las relaciones entre ambos países, miles de migrantes se han encontrado con la estigmatización en una sociedad que desarrolla mecanismos para contener las posibles 'amenazas' que representa su movilidad. Para tales fines, este artículo aborda tanto noticias e imágenes de diferentes medios de comunicación, como discursos políticos y noticias falsas que circulan mediante cadenas de WhatsApp que, en su conjunto, terminan por afianzar la percepción de amenaza en distintos sectores de la sociedad colombiana. Conclusiones: las políticas de solidaridad y ayuda que pregona el Estado van de la mano con mensajes contradictorios producidos en los medios que, en últimas, le presentan al público a una población indiferenciada que pone en peligro al cuerpo de la nación.

Palabras clave: migración, migrantes, Colombia, Venezuela, política, amenaza pública.

1 Escuela de Ciencias Humanas, Universidad del Rosario.

Autor de correspondencia: juan.ordonez@urosario.edu.co

2 Facultad de Ciencia Política, Gobierno y Relaciones Internacionales, Universidad del Rosario. 


\section{Abstract}

Introduction: This article addresses the political and mediatized construction of the "Venezuelan migrant" as a threat to public health and security in Colombia. Development: Since 2015, massive migration from Venezuela has forced Colombian society into an unprecedented situation in its recent history. Amidst the hyper-politicization of bilateral relations between the countries, thousands of Venezuelan migrants have crossed the border, only to encounter stigmatization in a society that is in the process of developing different mechanisms to contain the supposed "danger" they represent. We use digital news reports and images published by media outlets, political speeches, and "fake news" messages disseminated through WhatsApp to show how this perception of threat consolidates. Conclusions: We suggest that the State's push to address the problem with solidarity and aid goes hand in hand with contradictory messages produced by the media, which present the Colombian public with an undifferentiated population that threatens the body of the nation.

Keywords: Migration, migrants, Colombia, Venezuela, politics, public threat.

\section{Resumo}

Introdução: neste artigo propomos uma reflexão sobre a construção mediática e política da imagem do “migrante venezuelano" como ameaça à saúde e segurança pública n Colômbia. Desenvolvimento: a partir do ano 2015 a migração massiva de venezuelanos enfrenta à sociedade colombiana a uma situação inédita em sua história recente. No meio de um contexto atravessado pela hiperpolitização das relações entre ambos os países, milhares de migrantes se têm encontrado com a estigmatização em uma sociedade que desenvolve mecanismos para conter as "ameaças" que representa sua mobilidade. Para esses fins, o artigo aborda tanto notícias e imagens de diferentes meios de comunicação, quanto discursos políticos e notícias falsas que circulam através de cadeias de WhatsApp, que em conjunto terminam por afiançar a percepção de ameaça em distintos setores da sociedade colombiana. Conclusões: sugerimos que as políticas de solidariedade e ajuda que proclama o Estado vão da mão com mensagens contraditórios produzidos nos meios que, no final, apresentam ao publico uma população indiferenciada que põe em perigo ao corpo da nação.

Palavras-chave: migração, migrantes, Colômbia, Venezuela, política, ameaça pública.

\section{Introducción}

工n la cartilla Aprende a protegerte, el Ministerio de Salud colombiano define la prevención mero es la higiene, para mantener al margen el peligro; sigue el aislamiento, para no contaminar a los demás; y, finalmente, se promueve la asepsia de lo público, que básicamente implica mantener "limpios los objetos de uso común” y responsabilizarse individualmente de evitar entrar en contacto con otros. El mensaje es claro: para impedir el contagio "[...] nos toca a todos combatirlo [...]" (1). El peligro que encarna el virus representa, en este caso, una amenaza directa a lo que Scheper-Hughes y Lock han llamado el cuerpo individual (la experiencia subjetiva de cada persona) y el cuerpo social (los usos y representaciones compartidas que atan la 'naturaleza' del cuerpo al mundo social, y viceversa, donde el cuerpo 
saludable establece un modelo de integridad social). Pero, el virus también amenaza al cuerpo político, que para estas autoras se refiere a la regulación, administración y vigilancia de cuerpos individuales y colectivos (2). Este lenguaje, cargado de representaciones de amenaza, contención y profilaxis del contagio, tiene un poder central en la construcción de imaginarios sociales que se atarán en este texto a diferentes elementos de la crisis migratoria que desde 2015 ha traído cientos de miles de venezolanos a Colombia.

Este artículo busca hacer una reflexión inicial sobre la migración venezolana a Colombia desde la producción de la figura de los ‘migrantes’ en artículos de prensa (en sus versiones digitales), en algunas discusiones públicas de políticos colombianos, y mediante mensajes en cadenas de WhatsApp durante el periodo de 2017 a 2018, antes de las elecciones presidenciales. Se muestra cómo la llegada de ciudadanos venezolanos se articuló en estos espacios alrededor de la figura de amenazas a la nación colombiana, tanto en términos de seguridad, como de salud pública. Estas amenazas entretejen el miedo al 'castrochavismo' con la llegada de cuerpos que contagian y enferman a los colombianos, inclinando la balanza en la tensión entre compasión y represión común a las sociedades receptoras de migración (3). En este sentido, los tres niveles de análisis descritos por Scheper-Hughes y Lock parecen colapsarse sobre sí mismos para generar la imagen de una horda de personas que acecha las fronteras de la nación colombiana y que, incluso, penetran en su interior y amenaza a sus ciudadanos. La prensa y las redes sociales afianzan el imaginario del cuerpo individual de los colombianos que corre el riesgo de contaminarse y enfermar por el desorden que la migración ha generado en el cuerpo social. Las enfermedades que traen los migrantes, en esta lógica, desestabilizan la armonía social y traen patologías externas para ilustrar las fallas en el cuerpo político que no logra regular y disciplinar esta población. Hacia el final de este análisis, se plantea que, en este juego de imágenes y mensajes, el cuerpo de los colombianos afectados por la contaminación llega a representar el cuerpo de la nación en su totalidad. En este sentido, los medios y las redes sociales construyen una alteridad migrante que amenaza al orden nacional, una "materia puesta fuera de su sitio" que, sin embargo, también debe ser atendida e inscrita burocráticamente en el Estado $(4,5)$.

\section{Consideraciones metodológicas}

El material de prensa que se presenta fue recolectado como parte de una búsqueda temática, en el marco de una exploración inicial del tema migratorio en Bogotá. Se escogieron las versiones digitales de los tres únicos medios colombianos que tienen una amplia distribución nacional: El Tiempo, El Espectador y la revista Semana. Algunos debates universitarios que se mencionarán en el texto fueron, igualmente, reportados en estos medios. El objetivo de este trabajo no es atribuir intenciones políticas explícitas a ninguna de estas fuentes de prensa (salvo cuando replican los mensajes del Gobierno y de los candidatos presidenciales) sino que se busca tener 
un acercamiento a un análisis del cómo se construye la imagen del migrante —cómo se le atribuyen y asignan significados - en la forma en que se representa el problema migratorio venezolano para el público.

Los mensajes de WhatsApp que se presentarán al final del artículo se obtuvieron mediante contactos en diferentes regiones de Colombia, y de migrantes venezolanos en Bogotá. Se incluye también un mensaje cuya difusión ameritó incluso su publicación en los medios digitales de una popular emisora de radio. No se sabe el origen ni el autor de estos mensajes, ni se conocen las intenciones políticas (si las hay) que subyacen a su producción, pero fueron virales en la misma época en que los artículos que se citan aparecieron en la prensa. Esto permite afirmar que los artículos y mensajes en redes comparten, por lo menos, la misma temporalidad y contexto.

\section{Desarrollo}

\section{Crisis migratoria}

A partir de 2015, el flujo de venezolanos migrando hacia Colombia empezó a incrementar atípicamente, y cientos de miles de personas del vecino país empezaron a cruzar la frontera y a quedarse no solo a las zonas fronterizas, sino también en diferentes regiones del interior. En 2017, la Organización Internacional para las Migraciones (oIM) y el Gobierno calcularon el número de venezolanos en Colombia en 600000, una cantidad aproximada que no incluye solicitantes de asilo, ni puede más que estimar el número de migrantes irregulares que desborda toda capacidad de caracterización oficial (6). Porcentualmente, el $66 \%$ de los venezolanos que llegaron 'legalmente' a Colombia en 2017 se quedaron, la mayoría de ellos ingresaron por vía terrestre por los pasos fronterizos de La Guajira, Norte de Santander, Arauca y el Vichada (7). Estas cifras tampoco incluyen retornados nacionales colombianos y sus núcleos familiares que, habiendo migrado a Venezuela, regresaron con necesidades similares a las de los migrantes con nacionalidad venezolana. Estos 'retornados' son muchas veces venezolanizados, en el sentido de que son atendidos bajo los mismos programas de atención al migrante - desconociendo su nacionalidad y documentación colombiana-y se les dificulta reclamar derechos de nacionalidad para sus hijos y parejas. Incluso, algunas políticas los denominan connacionales, una forma atípica de diferenciar su ciudadanía a partir del hecho de residir un tiempo fuera del país.

Frente a la entrada de tantas personas, el Estado colombiano ha promovido públicamente la solidaridad y la compasión frente a la situación de los migrantes. "Vamos a extenderles una mano solidaria y decirles: hermanos, estamos con ustedes” fueron las palabras del presi- 
dente Santos desde la frontera en 2017, en una alocución que además advertía sobre los peligros de la xenofobia y de culpar a los migrantes por los problemas que se estaban generando en diferentes regiones del país (8). Sin embargo, esta solidaridad parece materializarse, en la práctica, como una excepcionalidad humanitaria que termina por crear una relación desigual, transitoria y temporal entre el Estado y los migrantes.

Esto se puede ver en la implementación del Permiso Especial de Permanencia (PEP) en sus dos primeras versiones ${ }^{3}$, ya que fue diseñado para regularizar migrantes que habían sobreextendido su permanencia legal en Colombia y que habían entrado al país antes del 28 de julio de 2017, fecha ampliada posteriormente por el Gobierno hasta el 2 de febrero de 2018 (6). Entre los requisitos para obtener el PEP estaban el haber pasado por un puesto de control migratorio oficial y haber sellado el pasaporte, cosa que excluyó a un número significativo de personas por dos razones: la primera es la fluidez y porosidad de una frontera de $2219 \mathrm{~km}$ que históricamente ha unido más que separado una amplia área entre los dos países (9). La segunda es que, para la mayoría de gente, obtener el pasaporte en Venezuela es casi imposible, por las dificultades burocráticas y económicas que representa, en un país cuyas instituciones han desarrollado mecanismos formales e informales para entorpecer los flujos migratorios hacia el exterior.

En otras palabras, el PEP extendió elementos de ciudadanía, que incluyen la posibilidad de inscribirse al sistema de salud (ya sea el régimen subsidiado o contributivo) y trabajar, a un número reducido de venezolanos que ya tenían un pasaporte vigente o los medios económicos y políticos para tramitar uno nuevo. Además, el PEP en este periodo asumía una temporalidad explícita de los migrantes en Colombia y se entendió desde el Estado como una extensión del permiso de estar en el país que podía ser renovado posteriormente. Esto resultó en 155572 solicitudes reportadas por la oim a febrero de 2018 y dejó por fuera un número indeterminado de migrantes que quedaron entonces clasificados como 'irregulares', con un acceso limitado a servicios de salud de urgencias y sin la posibilidad de trabajar legalmente. Entre febrero de 2017 y febrero de 2018 el Gobierno colombiano expidió, además, más de un millón y medio de Tarjetas de Movilidad Fronteriza (TMF), un instrumento pensado para controlar los tránsitos pendulares en la zona de frontera, que, sin embargo, terminó fomentando de forma indirecta el flujo de migrantes irregulares hacia el interior del país (6).

El diseño incipiente de políticas migratorias en Colombia puede ser entendido como un intento de reimaginar el orden nacional para lidiar con una población migrante significativamente más grande que cualquiera que haya existido en el país anteriormente (10). En su estudio de refugiados en Tanzania, Malkki propone entender el Estado nación como un sistema de

3 Una tercera versión del PEP promete regularizar a todos los migrantes irregulares que participaron en el Registro Administrativo de Migrantes Venezolanos (RAMv) finalizado en junio de 2018. Sin embargo, quienes no participaron se encuentran en la misma encrucijada de las versiones anteriores. 
clasificación que ordena a la población de diferentes formas. El “orden nacional de las cosas” es un fenómeno que tiene raíces culturales profundas y que enmarca 'la nación’ como una construcción que está anclada a geografías y temporalidades específicas (11). Para esta autora, los refugiados no caben de forma clara en el orden nacional, porque están desterritorializados, desarraigados de una 'localidad' específica y, por ende, en una indeterminación categórica. Como los refugiados que estudia Malkki, los migrantes venezolanos no son 'imaginados’ en Colombia como una población que se va a inscribir en ella, sino que tanto el Estado y los medios de comunicación parecen entenderla como una población que escapa a la crisis política y económica de su país y que solo se encuentran en Colombia mientras que la situación se resuelve. En otras palabras, están, pero no pertenecen.

Esta forma de inscribir a los migrantes en el Estado apunta a una aproximación a los venezolanos que se puede articular a otros debates alrededor de la evaluación moral de la diferencia en sistemas migratorios. En su análisis de los cambios en el sistema de asilo político europeo, Fassin sugiere que la compasión, articulada alrededor del refugio como un acto humanitario y no político, ha tomado el papel central en cómo se entiende el problema (3). Su caso se refiere al incremento de asilo otorgado por razones médicas frente al decrecimiento de asilo por cuestiones políticas. En su análisis, el punto central es que la obligación del Estado frente al reconocimiento político ha sido reemplazada por la solidaridad y el reconocimiento del sufrimiento. Vemos algo similar ocurriendo en Colombia, por lo menos en la forma en que se debate el tema en los medios, y es que la solidaridad que se pone en juego se presenta como un acto de generosidad colombiana, por encima del reconocimiento legal que por derecho tienen los migrantes. Más adelante se mostrará que este acto de generosidad tiene la potencialidad de ser presentado como un arma de doble filo que pone a la nación en riesgo.

La categorización dispuesta por el PEP genera una población de facto que se encuentra fuera del orden nacional (migrantes irregulares) por medio de un proceso burocrático diseñado para promover la inscripción de migrantes temporalmente en el Estado colombiano. En otras palabras, el PEP constituye una forma de solidaridad excluyente que legitima a ciertos migrantes temporalmente y deja otros en los márgenes del Estado donde pueden ser criminalizados por diferentes actores como la policía, el ejército, Migración Colombia ${ }^{4}$ y otros.

Sin embargo, las distinciones legales que establecen instrumentos como el PEP no determinan, necesariamente, la forma en que se discute el problema en la esfera pública. Por ejemplo, tanto los medios de comunicación, como las campañas presidenciales en el periodo antes de las elecciones de 2018, se referían en diferentes circunstancias a los venezolanos como una categoría homogénea. Esto ha contribuido a la noción de que la migración venezolana genera desorden en la nación y que constituye una amenaza desde diferentes frentes. Se empezará con una mirada a la forma en que la migración y la salud entran a cumplir un

4 La autoridad migratoria colombiana. 
papel importante en la promoción de una idea de contagio, para luego analizar la manera en la que se discute el problema migratorio como una amenaza a la seguridad.

\section{Salud y política migratorias}

La salud y la higiene han sido centrales a la gobernanza de la migración, desde su consolidación, como una problemática de la Modernidad, donde se construyeron sistemas de control y clasificación de poblaciones e individuos según percepciones de sus prácticas culturales y condiciones de salubridad (12). Algunos autores han atado estas políticas a prácticas coloniales de racialización que las potencias occidentales usaban sobre los espacios colonizados en la creciente expansión del poder económico y político de los países del Atlántico Norte, lo que adquirió una especial importancia a partir del siglo xix $(13,14)$. La transmisión de enfermedades contagiosas en un sistema geopolítico globalizado está imbricada en la conformación de áreas disciplinares como la epidemiología y sigue cumpliendo un papel importante en las formas en que se articulan políticas de control de los movimientos poblacionales, la inscripción de migrantes en los países receptores y los derechos al refugio $(3,15,16)$. Así, varios autores han resaltado la construcción de los y las migrantes por medio de presunciones sobre su género, sus prácticas de crianza, sexualidad y fertilidad y sus prácticas de higiene $(12,17,18)$. Uno de los casos más emblemáticos fue la estigmatización de los migrantes haitianos en las primeras décadas de la epidemia de SIDA y VIH $(19,20)$.

En Colombia, debido a los intereses de las élites, las condiciones geográficas y el conflicto interno ha habido bajos flujos migratorios a lo largo de su historia (10). Sin embargo, una revisión de decretos y leyes colombianas en las primeras décadas del siglo xx muestran una preocupación por la salud pública y la eugenesia. La Ley 48 del 3 de noviembre de 1920, por ejemplo, cita en su Artículo 7 varios incisos que conducirían a la inadmisibilidad de extranjeros al país. Estos incluyen "a los que padezcan de enfermedades graves, crónicas y contagiosas, tales como tuberculosis, lepra, tracome (y otras enfermedades similares no sujetas a cuarentena)" entre otros. La lista de inadmisibilidad incluía además “a los que sufran de enajenación mental, [...] demencia, manía, parálisis general; a los alcoholizados crónicos, a los atáxicos, a los epilépticos, a los idiotas, a los cretinos, a los baldados a quienes su lesión impide el trabajo”. En los años siguientes, el país vería surgir políticas y leyes que buscaban controlar, limitar o impedir la entrada a migrantes pertenecientes a las poblaciones desplazadas por la Segunda Guerra Mundial, racializados de diferentes formas por su etnicidad y por su religión, por medio de argumentos eugenésicos que primaban en la época (21-23). El orden nacional no debía incluir cuerpos enfermos o personas cuya raza, etnicidad y religión no concordaban con las de los ciudadanos colombianos. Curiosamente, las elites criollas comúnmente ostentaban como capitales simbólicos su contacto con otras naciones, pero en esa ambivalencia hicieron lo posible para restringir la llegada de quienes pudieran disputar sus privilegios (10). 
En la actualidad, los cuerpos venezolanos son estigmatizados en Colombia, por medio de mecanismos afines que pretenden impedir la penetración de cuerpos enfermos al país:

Para evitar la proliferación de enfermedades importadas de Venezuela, como ocurrió con el virus del sarampión, del que no se había tenido registro en el país desde 2015, el Instituto Departamental de Salud (IDS) de Norte de Santander habilitó este miércoles cuatro nuevos puestos de vacunación en los tres puentes internacionales del área metropolitana de Cúcuta y en una población fronteriza de la región del Catatumbo. (24)

Múltiples artículos de prensa reportan las fallas en los esquemas de vacunación de niños y adultos mayores que están llevando enfermedades a Colombia. Es notorio que tanto la política puesta en marcha en el artículo citado arriba, como el énfasis dado por el medio (el primer párrafo), buscan sembrar la idea de blindar a la nación desde la frontera, es decir, impedir que entre la 'amenaza'. El lenguaje militar está resaltado en un aparte del comentario del director del IDs, editado con relación al cuerpo del mismo artículo. Mientras que en el texto dice que buscan "[...] tratar de disminuir o diezmar la posibilidad de que ingresen pacientes con sarampión," en letra mucho más grande y resaltada con negrita se enfatiza "diezmar la posibilidad de que ingresen pacientes con sarampión” y se omite la palabra disminuir. El énfasis en una palabra militarista, cuyo significado de causar muerte es latente, tiene un efecto violento, donde se protege a la nación de la entrada cuerpos enfermos. Esto, refiriéndose a una enfermedad que el mismo artículo dice no ha tenido registro en Colombia desde 2015, tan solo tres años antes de la fecha del artículo.

El mismo medio reportó quince casos de sarampión en Colombia y resaltó que el Instituto Nacional de Salud informó "que los casos confirmados corresponden a personas extranjeras, puntualmente venezolanos [...]" (25). Los reportes no se refirieren a las distinciones que establece el Estado entre migrantes regulares y quienes están irregularmente, pareciera que epidemiológicamente la categoría es simplemente venezolanos. Esta forma de construcción de la migración como amenaza a la salud pública pasa entonces por homogenizar un conjunto poblacional complejo (los perfiles de los migrantes venezolanos están en las clases sociales más altas, hasta las más pobres), pero implica además asignar marcadores sociales a un grupo específico, desconociendo que pueden tratarse de características comunes a otros grupos que sí hacen parte de la nación.

La preocupación por los efectos de la migración venezolana sobre el sistema de salud colombiano y sobre la salud general es reiterativa. La llegada de tantas personas, que incluye enfermos crónicos, embarazadas, lactantes, personas que ejercen la prostitución y menores de edad o adultos mayores con esquemas de vacunación incompletos, aparecen en los medios como uno de los temas centrales que deben ser controlados. Los brotes de sarampión, específicamente, fueron ampliamente reportados como consecuencia de la llegada de personas que vienen de un sistema de salud deficiente $(26,27)$. Y mientras que estas preocupaciones están 
basadas en problemáticas epidemiológicas, no están desligadas de la forma en que se articula la salud pública en los imaginarios nacionales como una amenaza de contagio. Los artículos siguen lógicas técnicas, que, sin embargo, dejan claro que la salud del cuerpo social y de los individuos en Colombia está en peligro. El lenguaje militarista promueve la idea de un ataque, algo que se ampliará en la siguiente sección, donde se promueve la idea de una potencial invasión que debe ser evitada.

\section{Seguridad y migración}

En el marco de un conversatorio sobre la transformación de las Fuerzas Militares colombianas en el posconflicto, el general Bonett, antiguo comandante general de las Fuerzas militares, discutió acerca de la "Colombia profunda que no conoce nadie”. En su ponencia identificó a los militares como unos de los pocos testigos del Estado frente a las diferencias del país (no solo en lo que respecta a la violencia en su sentido típico, sino en las ausencias del Estado en otros aspectos). En su lista de las principales amenazas a la nación, el general preguntó:

“¿Cómo vamos a tocar el problema de Venezuela? [...] Ya el sarampión llegó a Risaralda [...] ¿Será una forma de guerra biológica? [...] Venezuela nos considera un enemigo, y nosotros no, por eso nuestras fronteras están abiertas [...] Entran personas, sin identificación y sin las normas a la entrada que se necesitan”. (28)

La amenaza militar, para el general, emerge como una forma de guerra biológica donde la entrada de personas sin identificación claramente atenta contra la nación. En su referencia a las fronteras, se puede inferir la necesidad de establecer más control para impedir la entrada de este nuevo adversario. La identificación acá responde al orden nacional, pues el Estado necesita controlar la población para poder gobernar. Identificar a los migrantes como parte de una guerra biológica es un recurso útil a la segregación y a la conformación de ciudadanías de segunda clase, que necesitan ser administradas, vigiladas y disciplinadas (2, 29, 30). Esta configuración del orden nacional es solo comprensible a partir de transformaciones que ocurren en dos niveles: el del cuerpo individual como objeto de disciplina y vigilancia, y el de la población como objeto de regulación, control y bienestar (2). En esta transformación "el territorio nacional se hace equivalente al cuerpo individual y el cuerpo político y el ciudadano se hacen uno” (31). Es decir, la amenaza al orden nacional está representada en las potenciales consecuencia para cada uno de sus ciudadanos.

La preocupación por la seguridad apareció en el centro de muchos debates políticos durante el periodo electoral en las campañas presidenciales colombianas de 2018. Candidatos, políticos y líderes de opinión de todas las tendencias debatieron la situación en Venezuela y sus efectos sobre Colombia, ampliamente (32-37). Algunos políticos trataron de establecer una asociación entre los migrantes venezolanos y la guerrilla del Ejército de Liberación Nacional (ELN), mientras que universidades y diferentes medios de comunicación organizaron 
eventos para discutir cómo afectarán los venezolanos la economía, la seguridad y el entorno laboral colombiano en un futuro cercano (38). De hablar de Venezuela como un Estado fallido, una dictadura y un problema de derechos humanos, los diferentes candidatos incluyeron advertencias de la posibilidad de que Colombia llegue a una crisis similar, y resaltaron el influjo de migrantes como un foco de inseguridad. La penetración de las patologías sociales y políticas venezolanas 'en muchas de estas instancias' se equiparó a los migrantes: "Nos están mandando los peores delincuentes”, dijo el entonces candidato presidencial Germán Vargas Lleras en un evento reportado por los medios nacionales (39). Otro hito en la campaña electoral fue la aparición de vallas publicitarias promocionando al candidato por el Centro Democrático en Bucaramanga, Bogotá y otras regiones del país con mensajes como "No quiero vivir como venezolano" o "Para que Colombia no sea otra Venezuela".

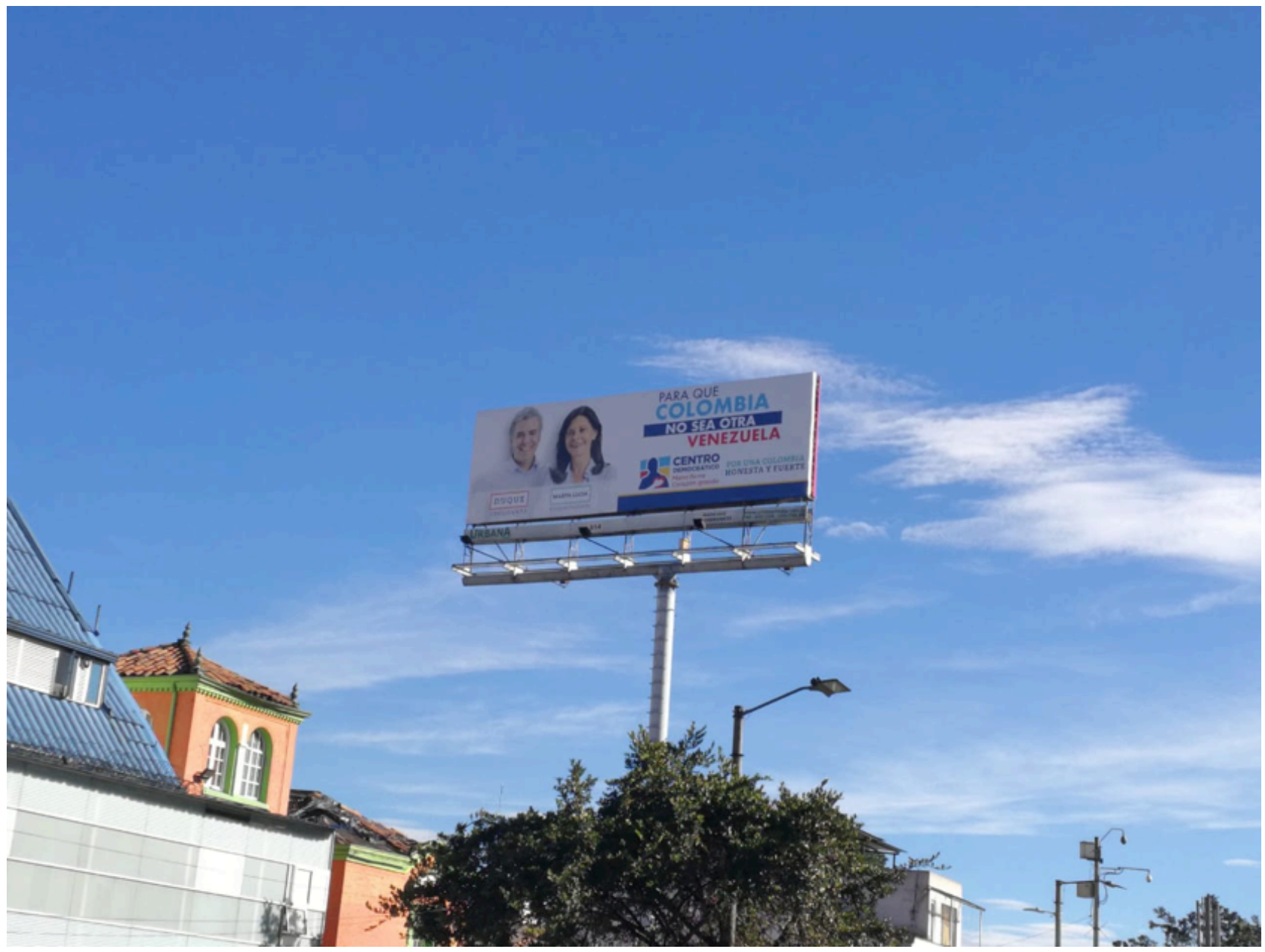

Figura 1. Valla Publicitaria ubicada sobre la Avenida Caracas en Bogotá, año 2018 


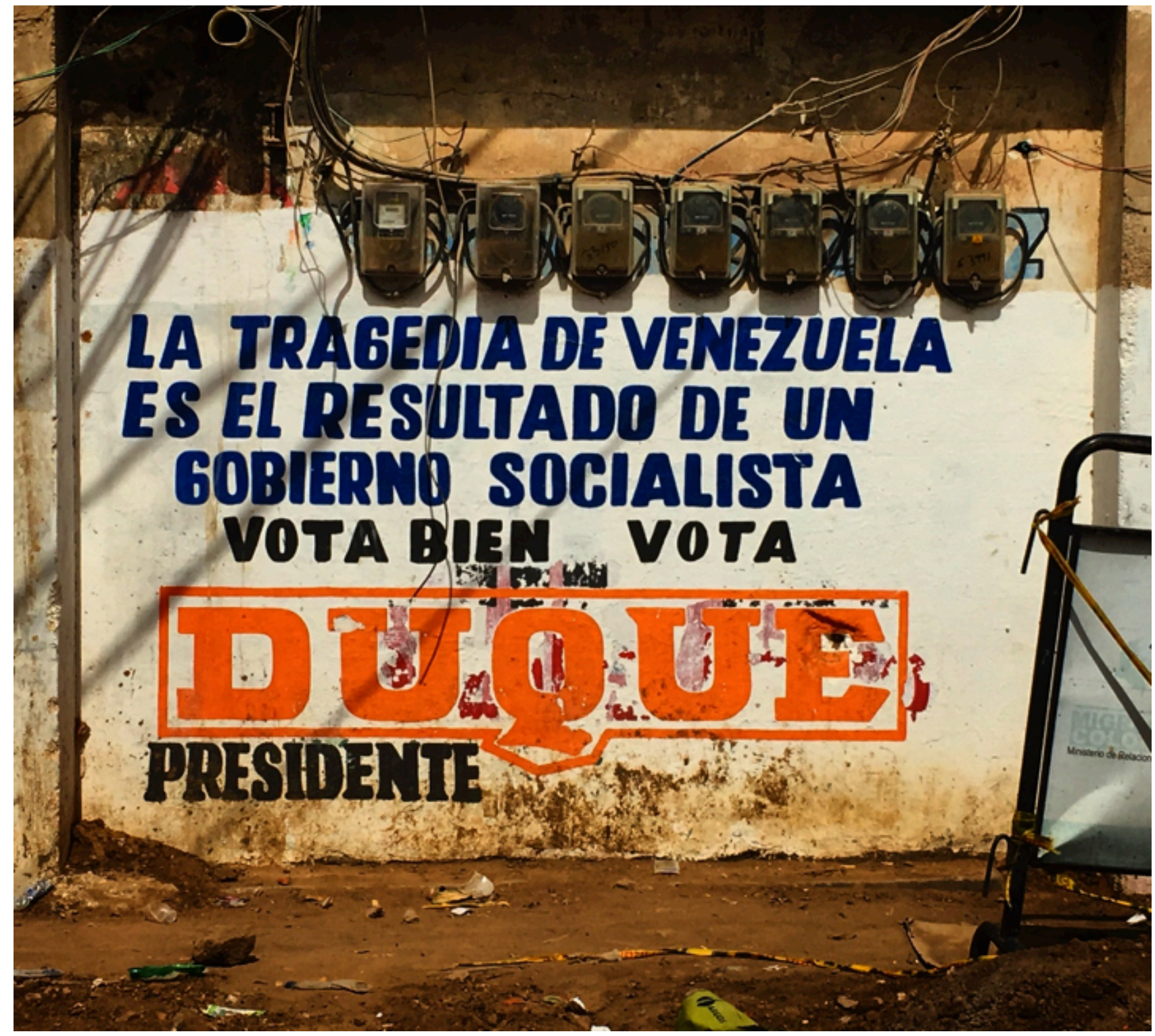

Figura 2. Muro con publicidad política, Paraguachón, La Guajira (justo a la entrada a Colombia en la frontera con Venezuela, año 2018)

\section{(Des)orden nacional}

Como se ha mostrado, el problema migratorio en Colombia se ha articulado alrededor de las problemáticas de salud pública y de seguridad. En conjunto, se puede inferir una asociación de los males sociales y políticos venezolanos con una amenaza directa a la nación colombiana. Así, mientras el PEP y la TMF en 2017 y 2018 aparecieron como una respuesta solidaria a la entrada de tantas personas, la politización en Colombia de la situación en Venezuela puso en cuestión la percepción de los colombianos sobre quiénes eran los venezolanos que estaban llegando al país. Literalmente, aparece la noción de un desorden nacional que debía ser controlado por quien fuera a ganar las elecciones. "Hay que poner orden ya", concluyó nuevamente Vargas Lleras en una columna del diario El Tiempo (38). 
El desorden nacional es evidente en diferentes titulares de prensa. La revista Semana publicó títulos como: "Delincuencia, el efecto colateral de la migración venezolana" o "Alerta por aumento de venezolanos en la delincuencia colombiana” $(40,41)$. Otro ejemplo de estos se tomó de un artículo de El Tiempo que reza: “¿Qué opina de la ola de delincuencia que involucra a los venezolanos? (42). Estos y muchos otros artículos del periodo estudiado aparecen en lo que se podría describir como una avalancha mediática que encontró en la agenda venezolana un tema de atracción entre sus lectores. Aunque los dos artículos de Semana son moderados frente a la forma en que reportan el problema, los encabezados crean una sensación de urgencia y amenaza. Además, los titulares son seguidos por imágenes que dan el mismo mensaje, un hombre joven mirando hacia el piso, sin esperanzas y sosteniendo un documento venezolano junto a su preregistro (TMF) en el primer caso, y una protesta agresiva donde la vestimenta de los participantes (camiseta de la selección de fútbol venezolana y cachucha con una $V$ y los colores de la bandera venezolana) deja claro que "ahí vienen”. Este efecto de la 'horda' que acecha la frontera muestra tumultos de personas aglomeradas de forma desordenada alrededor de carpas o vallas con las insignias de Migración Colombia.

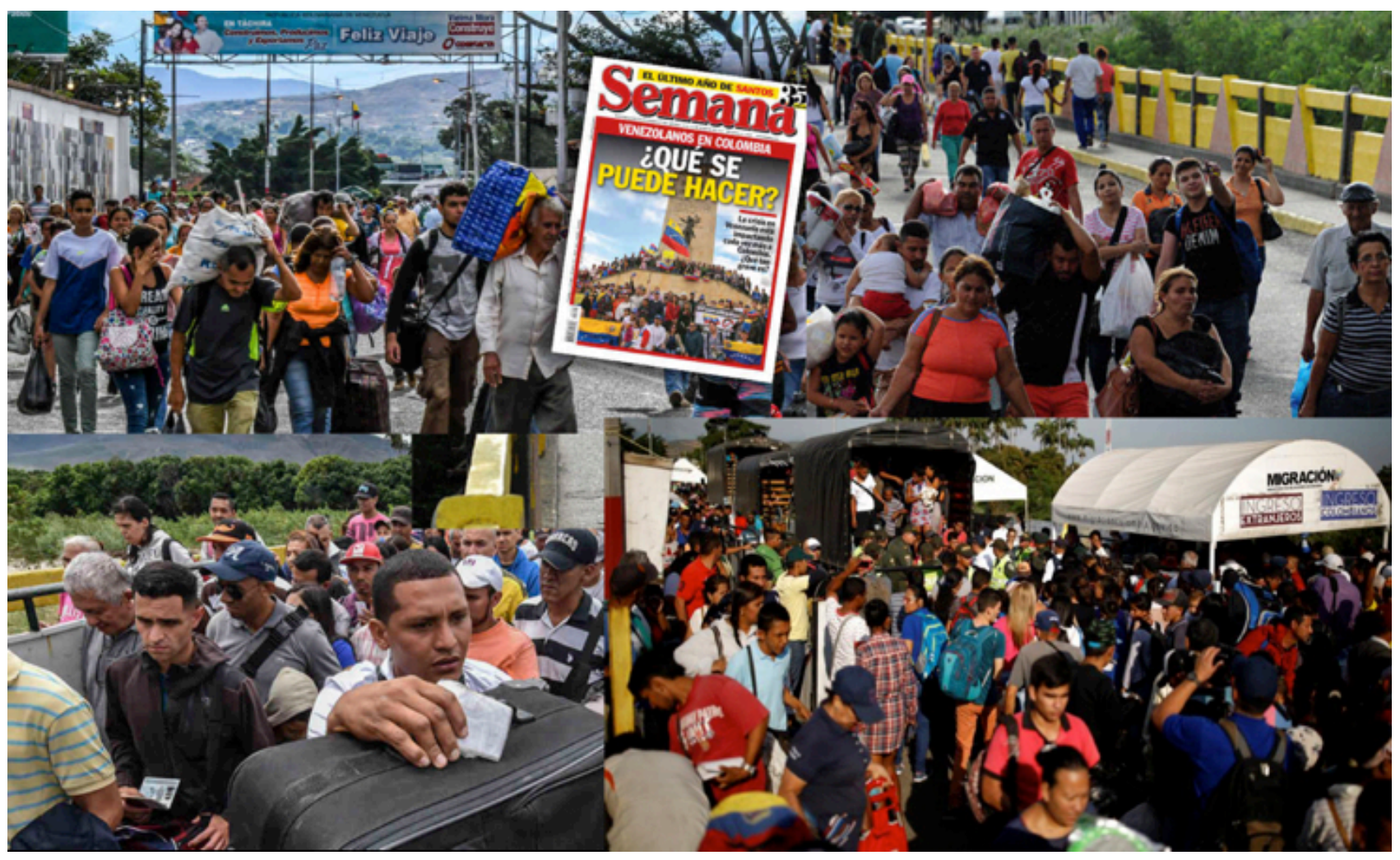

Figura 3. Collage de fotografías que publicó la revista Semana, año 2018

La forma en la que se reporta la migración, al igual que cualquier temática, no está libre de intenciones, sean explícitas o parte de los discursos hegemónicos de la nación (31, 43). Chávez, por ejemplo, ha mostrado que las portadas de revistas estadounidenses incrementan su cobertura de la migración (y el tono alarmista del mensaje que transmiten visualmente) en 
los momentos de crisis económica y que disminuyen el tono en momentos de afluencia (43). Por su parte, Weiss sugiere que los reportajes de ataques terroristas en Israel se articulan con discursos religiosos alrededor de nociones del cuerpo, sus excreciones y la impureza en artículos periodísticos que terminan equiparando los cuerpos de las víctimas con el cuerpo de la nación (31). Así, los medios de información cumplen un papel central en la construcción de representaciones colectivas y las reacciones de la sociedad a los problemas reportados.

En el caso de las fotos descritas de la horda frente a las vallas, las tradicionales barreras que son dibujadas alrededor de los migrantes, como los puestos fronterizos, la documentación, las diferencias culturares, hoy se materializan en "símbolos de nacionalidad” mucho más sutiles, que resultan útiles a la violencia colectiva contra un otro extranjero (5). En estas imágenes, es la nación colombiana la que está bajo el acecho de las hordas, personas que vienen de un socialismo fallido, enfermos, a delinquir o afectar la política nacional.

Las enfermedades y la inseguridad ofrecen, en este sentido, “un modelo de desarmonía social, conflicto y desintegración” como bien lo han dicho Scheper-Hughes y Lock (2). Tal modelo claramente contrasta con el lenguaje de solidaridad y compasión que usa el Estado y algunas organizaciones civiles para concientizar a la población colombiana y justificar sus respuestas al problema. La contradicción ofrece un potencial casi explosivo para el surgimiento de xenofobia y discriminación, pues los migrantes quedan atrapados entre ser los 'hermanos' merecedores de generosidad y ser los ‘peores delincuentes'. En los mensajes de WhatsApp que se presentarán a continuación, se puede ver la forma en la que los venezolanos transitan entre estas categorías y que no les permiten situarse claramente dentro del orden nacional.

\section{De los medios a las redes sociales}

Los mensajes contradictorios que contraponen la amenaza política y a la salud con la solidaridad tienen un efecto de escándalo. Medir el impacto que esto tiene sobre la imagen del migrante venezolano en Colombia es difícil y tal vez prematuro en este momento. Sin embargo, se pueden sugerir algunos elementos importantes que se vieron en mensajes de WhatsApp diseminados en los meses antes de las elecciones de 2018.

Los mensajes virales de WhatsApp cumplen con tres características que se consideran útiles al objetivo de esta investigación. En primer lugar, en el contexto actual las personas se informan principalmente por medio de sus redes sociales y la información que se comparte termina siendo replicada y recordada ampliamente entre sus receptores. WhatsApp brinda, además, un elemento de confianza a quienes reciben el mensaje, en tanto que la información es compartida por un contacto conocido, alguien que lo replica como un ejercicio de solidaridad de contenidos, lo cual para algunos ya es de por sí un criterio de validez. Finalmente, la velocidad de réplica de estos mensajes y la forma en la que demuestran las conexiones 
multiniveles de la sociedad permiten que personas que en apariencia no conforman una misma red estén conectadas mediante la circulación de los contenidos, sin conocer la fuente original. En síntesis, estos mensajes sobre la migración venezolana se extienden viralmente y configuran la percepción de un sector de la sociedad colombiana.

El primer mensaje apareció en la coyuntura electoral, donde surgieron rumores que aseguraban que los migrantes venían financiados por el Gobierno de Maduro a cedularse para votar por Gustavo Petro, el candidato de la izquierda (44). Empieza una mujer hablando con angustia y concluye en lágrimas:

Querida familia [...] ustedes saben que yo vivo de alquilar apartamentos amoblados, y este mes ha sido impresionante la cantidad de venezolanos que han venido a ocupar estos inmuebles, yo al principio alquilé porque no sabía [...], yo me imaginaba que porque hay tanta crisis de vivienda, etcétera, pues yo dije bueno voy a alquilarles incluso más económico, voy a buscar la forma de ayudarlos, les regalé camitas, ayudé a tantas personas, sinceramente no sabía cuál era el propósito o el trasfondo que había detrás de esta estampida de venezolanos que hay aquí. [...] lo que [... ] me abrió los ojos [...] fue hace apenas una semana. Me llamó uno de los dirigentes de esos grupos y me dio las gracias por apoyar a su pueblo, porque yo no sabía, me dijo: "Ay mira, gracias porque sabemos que tú nos estás apoyando, que tú nos estás colaborando, que nos has podido alquilar tus apartamentos, necesito uno en especial que tenga una gran capacidad de personas" [...] "Ellos vienen solamente a cedularse y ellos van a apoyar a Colombia votando por Petro, por todo lo que es el comunismo", y dándome las gracias [...] yo me quedé fría, yo dije ¿cómo así? y me dijo: "sí, de hecho te vamos a tomar por tres meses los apartamentos, todos. Para que tú estés tranquila de que se te va a pagar, quien nos está dando el aval es nuestro gobierno. Maduro se encarga de pagar, o sea no tengas problema ni miedo con nosotros, nosotros te vamos a pagar todo [...]". Pero yo dije, pero yo no estoy apoyando eso, porque sinceramente no estoy así como de acuerdo con lo que ustedes están haciendo, entonces me contestó, este dirigente [...]: “¿y por qué?, si igual ustedes nos hicieron el favor cuando Chávez convocó a colombianos a que se fueran a cedular allá para que votaran por él, y de hecho él les dio dinero y eso, entonces a nosotros nos están dando provisiones económicas a todos los que vengamos a apoyar a Venezuela, en luchar para que el comunismo se establezca, o sea nosotros queremos es ayudar a Colombia". Y yo, iqué!, le dije, ay disculpe, te llamo en un momentico. Le cuento que lloré, y lloré, y lloré (continúa hablando con voz llorosa). Después llamé y les dije "sabe, qué ya tengo comprometidos los apartamentos”, y me tocó desistir y estoy sacando esta gente. Estoy sacando esta gente, pero yo no sabía, que estaba de bruta promoviendo y ayudando todos estos venezolanos, no sabía que estaba apuñaliando [SIC] a mi país. (44)

Acá se ven los efectos de la solidaridad y la compasión. De pensar que está ayudando, la mujer 'despierta' a darse cuenta de que se han infiltrado: los venezolanos penetran la nación para contaminarla de comunismo, pasan de ser arrendatarios a ser 'dirigentes', por ejemplo. El mensaje empieza dirigido a la 'querida familia’ de la señora, pero su amplia distribución 
más bien dice que esa familia es Colombia, se dirige al cuerpo social y con angustia advierte de las intenciones reales detrás de la migración. La solidaridad tiene sus costos, de buscar la forma de ayudarlos, la mujer pasa a estar 'de bruta' ayudando a penetrar al comunismo.

Los dos mensajes siguientes son muy similares y llegaron desde diferentes partes de la frontera entre Colombia y Venezuela. En las grabaciones hablan hombres con acento de la región Caribe colombiana con un tono de urgencia:

Informamos desde Pailitas, Cesar, por favor querido público (menciona otras poblaciones). Soltaron los presos de Venezuela por parte de Maicao, por Puerto Santander y por la parada por Cúcuta. Le avisamos a todos los habitantes de Pailitas, por favor, tener mucha atención, esas personas que salieron de la cárcel salieron armadas con cuchillos, garrotes, robando al que sea, ellos son delincuentes, enfermos, tuberculósicos, son tísicos, tienen SIDA. Ojo, los habitantes de Pailitas, mucha atención con personas extrañas [...] que no conozcan. Por favor, a trancar bien las puertas, por favor ir a donde una persona [...] que tenga una sierra y mandar a hacer unos polines gruesos para trancar la puerta, porque están forzando las puertas, las están dañando [...].

Oye este comunicado es para todo el mundo (dice que en Venezuela abrieron las cárceles). Están enfermos, se estaban muriendo allá mismo, el Gobierno mandó abrir todas las cárceles de Venezuela. $\mathrm{O}$ sea, esa gente se ha regado en todo [...] vienen para acá para Colombia [...] esa gente viene con hambre, con ganas de atracar, con ganas de todo y vienen hasta enfermas y todo también. Con mucho cuidado en las casas, teniendo siempre las puertas cerradas con reja, ojo los niños, ojo todo. Ya saben, este comunicado es verdad, no es mentira, así que difundan este mensaje [...].

Ambas grabaciones describen el mismo evento, la salida de presos de las cárceles venezolanas y su inminente llegada a Colombia. Se ha puesto énfasis en los apartados donde la 'criminalidad' de los migrantes se articula alrededor de la noción de que 'viene una horda', pero es notorio que los mensajes incluyen las condiciones de salud de los venezolanos, especialmente en el primer caso que menciona enfermos de tuberculosis y siDA. Las grabaciones le hablan a un 'querido público' y a un 'todo el mundo' indeterminados, es decir, le hablan a la nación entera (en referencias más localizadas a la zona fronteriza), y terminan pidiéndole a la gente que se atrinchere para evitar que los migrantes entren a sus casas y protegerse de la profanación de entes 'sucios', tanto en el sentido moral como en el de salud. Esta necesidad de responsabilizarse por la asepsia social está tácitamente jugando con las imágenes presentadas en las fotos y reportajes de personas aglomeradas alrededor de las vallas de Migración Colombia rompiendo la barrera y penetrando violentamente la nación.

El tercer mensaje es mucho más largo y habla una mujer bogotana. Fue ampliamente diseminado en Bogotá y llegó por medio de migrantes que trabajan informalmente en Transmilenio, el sistema de transporte público al que se refiere la señora. La grabación está llena de marcadores de clase, el acento de la mujer, la zona de la ciudad donde dice vivir, el 
hospital al que lleva a su hijo y la universidad donde este estudia son referencias bogotanas a la clase alta. Acá no hay tono de urgencia, sino que habla una madre preocupada, tratando de difundir su experiencia para que otros protejan a sus hijos:

Eh, buenos días a todos, eh, estoy enviándole esta información absolutamente a todos los contactos que tengo [...] porque es muy grave lo que está pasando en Transmilenio, es una nueva modalidad de robo, de violación de niñas, de niños, de asesinato en Transmilenio, de atracos, eh, por medio de los venezolanos. Hay redes que están trabajando con ellos. Ellos mismos se han inventado sus propios grupos y a mi hijo le pasó el día miércoles en las horas de la tarde, nosotros vivimos al norte de Bogotá. Y venían en el Transmilenio más o menos a las 4:30 para su casa desde la Universidad Javeriana donde estudia él, eh un venezolano se está subiendo con una niña [...] "que tiene hambre, que no tiene trabajo", todos se saben ya la historia. $\mathrm{Y}$ vendiendo unas chocolatinas marca $\mathrm{x}$, nada conocida, entonces mi hijo fue muy ingenuo tal vez, y su compasión lo movió a comprarle una de las famosas chocolatinas y cometió el gravísimo error, no solo de comprarle, sino de consumirla delante del tipo. Eh, cuando llegó a la casa empezó muy desubicado (describe los síntomas de estar drogado) mi hijo no consume drogas alucinógenas y tampoco hace uso del alcohol en su vida, es una persona que trabaja, que hace deporte y se cuida muchísimo en este sentido (sigue la descripción de los síntomas). Me rogaba que le llamara una ambulancia y me decía "no me dejes morir" (Llega el papá y lo llevan a la Clínica del Bosque). Gracias a Dios vomitó de una manera impresionante y este vómito hizo que el eliminara todo el narcótico o la porquería que le hayan suministrado en esa basura, no sabemos qué es [...]. Eh, el médico que nos atendió nos dijo "Si, hay una modalidad de los venezolanos y también de gente de acá, son unas redes y se suben todos a Transmilenio (les explica el sistema de los atracos)" ellos tienen todo untado con unos alucinógenos fuertes y al solo toque de un esfero, de un cuaderno, de cualquier cosa que vendan y muy especialmente al consumo de las famosas cosas que venden, ya tienen tanto de manera externa como dentro mismo alimento, si se puede decir, o la cosa que consumen ya va esa droga (explica cómo funciona la droga y cómo se comunican entre atracadores para seguir a la víctima). Obviamente se ve la señora decente con un niño, la señora bien vestida o el tipo, lo que sea, y más adelante los cogen, no solamente los atracan sino los están violando. Es lo que me decía el médico han llegado cosas a la del Bosque impresionantes (sigue explicando) los cogen como a una presa y lo que le pasó a mi hijo (describe los síntomas nuevamente). (Dice que en los exámenes no encuentran nada). Pero la orina sí salió muy turbia, entonces el médico me decía que ahí estaba toda la evidencia, pero lo que a él lo salvó fue su masa corporal, el estado que tiene tan atlético, la cantidad de vómito y yo digo que fue Dios. Entonces por favor difúndanlo, no les compren, no les hablen, no les permitan que pasen cerca de ustedes porque están empezando a [...] con el contacto ya están ellos, tienen cosas que van presas de esto y cuídense mucho porque hoy fue mi hijo y ojalá que nunca sean los de ustedes.

Este mensaje describe el envenenamiento de un estudiante al que lo 'movió su compasión' a ayudar a un venezolano. Un cuerpo joven, atlético, trabajador y libre de 'vicio' es penetrado 
por la 'porquería' que venden los venezolanos y se salva por casualidad y gracias a su estado físico, al vómito y a Dios. Termina advirtiendo de la contaminación que implica entrar en contacto con los venezolanos - la solidaridad ensucia y contagia-y pidiéndole a todos que cuiden a sus hijos de esta nueva amenaza de atraco y violación. El cuerpo del estudiante es el cuerpo de la nación, saludable (desde el 2015 no teníamos noticia del sarampión) libre de vicio y lleno de compasión, un error que casi le cuesta la vida. "No les hablen, no les compren, no los toquen", el mensaje es claro, "protéjanse” de "esa” gente que está aquí fuera de su sitio.

\section{Conclusiones}

$\mathrm{L}$

os migrantes venezolanos han emergido en los medios de comunicación y en el debate político de las elecciones colombianas como una categoría homogénea de cuerpos que acechan la seguridad y la entereza del cuerpo social colombiano. La solidaridad, entendida como una forma de generosidad excepcional que ofrece el Estado y la sociedad colombiana, en general, ha entrado en el lenguaje popular como una falla que amenaza el cuerpo político, y la compasión colombiana es retribuida con enfermedad, desarticulación social y con la amenaza del castrochavismo.

Así, mientras el Gobierno promueve la solidaridad con los "hermanos” y muestra las cifras de su reconocimiento, resaltando los avances en extender el acceso a quienes tienen PEP al sistema bancario, a la educación y al sistema de salud, 'los venezolanos' — término genérico que no distingue las categorías de legalidad o irregularidad — aparecen en los medios y en las redes sociales como amenazas a la nación. Estas amenazas implican una encrucijada donde la solidaridad, mal recibida, constituye un peligro de polución al cuerpo de la nación (11).

De la misma forma que en la cartilla del ministerio de salud se enseña sobre la prevención de la influenza, la sociedad colombiana parece estar enfrentando la migración venezolana como un problema de salud pública y de seguridad nacional del que debe protegerse. Los reportajes y referencias a las dolencias físicas y sociales que trae esta población construyen imágenes de tumultos de personas acechando las fronteras y derramándose desordenadamente por el territorio nacional. En estas imágenes hay que mantener al margen el peligro y practicar una asepsia de lo público para prevenir el contagio que implica recibir un 'otro' migrante en Colombia. En otras palabras, los migrantes venezolanos son representados en las fuentes que hemos citado como "materia fuera de su sitio". Este proceso probablemente seguirá en curso por un buen tiempo, y las representaciones de amenaza, contención y profilaxis prometen atraer la atención de diferentes públicos en el país que pueden usar estos imaginarios, unos más politizados que otros, para movilizar la idea de que es el cuerpo de la nación el que está bajo amenaza y que el país no puede (o no debe) pensar a los "hermanos venezolanos" como parte del orden nacional. 


\title{
Descargos de responsabilidad
}

\author{
T os autores de este trabajo asumen la responsabilidad de lo publicado y la Revista de \\ LCiencias de la Salud no asume ninguna responsabilidad.
}

\section{Referencias}

1. Colombia, Ministerio de Salud. "Aprende a Protegerte”. 2013 [citado 2018 jun 07]. Disponible en: https:/www.minsalud.gov.co/Documentos\%20y\%20Publicaciones/ CARTILLA\%20APRENDE\%20A\%20PROTEGERTE.pdf

2. Scheper-Hughes N, Lock MM. The Mindful Body: A Prolegomenon to Future Work in Medical Anthropology. Med Anthropol Q 1987;1:6-41. Doi: doi.org/10.1525/maq.1987.1.1.02a00020fassi.

3. Fassin D. Compassion and Repression: The Moral Economy of Immigration Policies in France. Cult Anthropol 2005;20:362-87.

4. Douglas M. Pureza y peligro: un análisis de los conceptos de contaminación y tabú. Madrid: Siglo Veintiuno de España Editores; 1973.

5. Das V. Life and Words: Violence and the Descent into the Ordinary. Berkeley: University of California Press; 2006.

6. Unidad de Análisis Migratorio de la Oficina Regional de la oim para América del Sur. Tendencias Migratorias Nacionales en América del Sur: República Bolivariana de Venezuela. oIm; 2018.

7. Ozkan M. Colombia y una buena política de migración [internet]. El Espectador (Bogotá) 2018 [citado 2018 jun 07]. Disponible en: https://www.elespectador.com/noticias/el-mundo/colombia-y-una-buena-politica-de-migracion-articulo-735750

8. Vargas JR. Santos pide "no caer en la xenofobia” con venezolanos y hace un llamado a la solidaridad [internet]. 2017 [citado 2018 jun 07]. Disponible en: https://noticias.caracoltv. com/colombia/santos-pide-no-caer-en-la-xenofobia-con-venezolanos-y-hace-un-llamado-la-solidaridad

9. Ramirez S. Las Zonas de Integración Fronteriza de la Comunidad Andina. Comparación de sus alcances. Estud Políticos 2008;135-69.

10. García Estrada R de J. Los Extranjeros en Colombia: Su Aporte a la Construcción de la Nación (1810-1920). Bogotá: Planeta; 2006.

11. Malkki L. Purity and Exile. Chicago: University Of Chicago Press; 1995.

12. Horton S, Barker JC. "Stains" on their self-discipline: Public health, hygiene, and the disciplining of undocumented immigrant parents in the nation's internal borderlands. Am Ethnol 2009; 36:784-98. Doi: 10.1111/j.1548-1425.2009.01210.x

13. Anderson W. Excremental Colonialism: Public Health and the Poetics of Pollution. Crit Inq 1995;21:640-69. 
14. Stern AM. Eugenic Nation: Faults and Frontiers of Better Breeding in Modern America. Berkeley: University of California Press; 2005.

15. Handley MA, Grieshop J. Globalized migration and transnational epidemiology. Int J Epidemiol. 2007;36:1205-6. Doi: 10.1093/ije/dym027

16. Mason KA. Mobile Migrants, Mobile Germs: Migration, Contagion, and BoundaryBuilding in Shenzhen, China after sars. Med Anthropol 2012;31:113-31. Doi: 10.1080/01459740.2011.610845

17. Pessar PR, Mahler SJ. Transnational Migration: Bringing Gender In. Int Migr Rev 2003;37:812-46. Doi: 10.1111/j.1747-7379.2003.tb00159.x

18. Chavez LR. A Glass Half Empty: Latina Reproduction and Public Discourse. Hum Organ 2004; 63:173-88. Doi: 10.17730/humo.63.2.hmk4m0mfey10n51k

19. Farmer P. Infections and Inequalities: The Modern Plagues, Updated with a New Preface. Updated edition. Berkeley: University of California Press; 2001.

20. Farmer P. AIDS and Accusation: Haiti and the Geography of Blame, Updated with a New Preface. First edition. Berkeley: University of California Press; 2006.

21. Bibliowicz A. Intermitencia, ambivalencia y discrepancia: historia de la presencia judía en Colombia. Am Lat Hist Mém Cah [internet]. 2001 [citado 2019 abr 22]. Disponible en: http://journals.openedition.org/alhim/535

22. Hernández Gracía JÁ. Emigración Judía en Colombia en los años 1930 y 1940. Un caso particular: Los Polacos. Persamiento Cult 2007;10:177-90.

23. Ardila G. Presentación. In: Ardila G, editor. Colomb. Migr. Transnacionalismo Desplazamiento, Bogotá: Universidad Nacional de Colombia, Facultad de Ciencias Humanas, Centro de Estudios Sociales: Ministerio de Relaciones Exteriores: Fondo de Población de las Naciones Unidas; 2006. p. 23-38.

24. El Tiempo. Habilitan cuatro puntos de vacunación en la frontera con Venezuela. El Tiempo [internet]. 2018 [citado 2018 jun 08]. Disponible en: http://www.eltiempo.com/ colombia/otras-ciudades/habilitan-cuatro-puntos-de-vacunacion-en-la-frontera-con-venezuela-196536

25. El Tiempo. Casos se sarampión que se han confirmado en Colombia - Salud - Vida - El Tiempo [internet]. 2018 [citado 2018 jun 08]. Disponible en: http://www.eltiempo.com/ vida/salud/casos-se-sarampion-que-se-han-confirmado-en-colombia-209902

26. El Espectador. Colombia tendrá plan de salud para inmigrantes. Elespectadorcom [internet]. 2018 [citado 2018 jun 11]. Disponible en: https://www.elespectador.com/noticias/ salud/colombia-tendra-plan-de-salud-para-inmigrantes-articulo-738853

27. Semana. El impacto del éxodo de venezolanos [internet]. 2017 [citado 2017 sep 07]. Disponible en: http://www.semana.com/nacion/articulo/venezolanos-cruzan-la-frontera-en-busca-de-libertad-comida-y-salud/535377

28. Bonett MJ. El papel de las fuerzas militares en el Posconflicto 2018. Presentado en Universidad del Rosario 2018 mar 20; Bogotá.

29. Agamben G. Homo Sacer: Sovereign Power and Bare Life. Stanford: Stanford University Press; 1998. 
30. Foucault M. Seguridad, territorio, población. Buenos Aires: Fondo de Cultura Económica; 2006.

31. Weiss M. The Body of the Nation: Terrorism and the Embodiment of Nationalism in Contemporary Israel. Anthropol Q 2002;75:37-62. Doi: 10.1353/anq.2002.0022

32. Mejía Vergnaud A. ¿Es posible que Colombia llegue a estar como Venezuela? BLU Radio [internet]. 2017 [citado 2018 jun 08]. Disponible en: https://www.bluradio.com/opinion/ vamos-volvernos-otra-venezuela-151214

33. Agencia EFE. Dictadura: Álvaro Uribe dice que en Venezuela el diálogo ha "fortalecido a la dictadura” W Radio [internet]. 2018 [citado 2018 jun 08]. Disponible en: http:// www.wradio.com.co/noticias/actualidad/alvaro-uribe-dice-que-en-venezuela-el-dialogo-ha-fortalecido-a-la-dictadura/20180210/nota/3709351.aspx

34. Agencia EFE. Iván Duque llama a elegir entre su modelo o Venezuela [internet]. 2018 [citado 2018 jun 08]. Disponible en: https://www.youtube.com/watch?v=BeskrX84FlE

35. Espinoza JE. ¿Está cerca Colombia de convertirse en Venezuela? El Espectador [internet]. 2016 [citado 2018 jun 08]. Disponible en: https://www.elespectador.com/opinion/ opinion/esta-cerca-colombia-de-convertirse-en-venezuela-columna-656929

36. Revista Semana. El fantasma del castrochavismo. Revista Semana [internet]. 2017 [citado 2018 jun 08]. Disponible en: https://www.semana.com/nacion/articulo/colombianos-creen-que-el-pais-se-puede-convertir-en-venezuela/528035

37. Ruiz Perea AM. Por qué no nos vamos a volver Venezuela. Revista Semana [internet] 2016 [citado 2018 jun 08]. Disponible en: https://www.semana.com/opinion/articulo/ ana-maria-ruiz-perea-por-que-no-nos-vamos-a-volver-venezuela/492562

38. Vargas Lleras G. Columna de opinión: Sobre eln y Venezuela, hay que poner orden ya. El Tiempo [internet] 2018 [citado 2018 jun 08]. Disponible en: http://www.eltiempo.com/ opinion/columnistas/german-vargas-lleras/sobre-eln-y-venezuela-hay-que-poner-ordenya-german-vargas-lleras-184028

39. Guerrero M. Candidatos presidenciales respondieron sobre crisis en Venezuela. El Espectador [internet] 2018 [citado 2018 may 31]. Disponible en: https://www.elespectador.com/noticias/el-mundo/candidatos-presidenciales-respondieron-sobre-crisis-en-venezuela-articulo-752095

40. Revista Semana. Delincuencia: el efecto colateral de la migración venezolana. Revista Semana [internet]. 2018 [citado 2018 jun 08]. Disponible en: https://www.semana.com/ nacion/articulo/crisis-en-venezuela-delincuencia-en-colombia/556750

41. Revista Semana. Fiscalía alerta por aumento de venezolanos en la delincuencia colombiana. Revista Semana [internet]. 2018 [citado 2018 jun 08]. Disponible en: https://www. semana.com/nacion/articulo/fiscalia-alerta-por-aumento-de-venezolanos-en-la-delincuencia-colombiana/556251

42. Bernal MC. ¿Qué opina de la ola de delincuencia que involucra a los venezolanos? El Tiempo [internet]. 2018 [citado 2018 jun 08]. Disponible en: http://www.eltiempo.com/ bogota/que-opina-de-la-ola-de-delincuencia-que-involucra-a-los-venezolanos-en-bogota-callejeando-180048

43. Chavez LR. Covering Immigration: Popular Images and the Politics of the Nation. Berkeley: University of California Press; 2001. 
44. La FM. ¿Campaña sucia? Cadena de WhatsApp advierte de venezolanos registrados para votar por presidente. La FM [internet]. 2018 [citado 2018 jun 08]. Disponible en: https:// www.lafm.com.co/politica/campana-sucia-cadena-de-whatsapp-advierte-de-venezolanos-registrados-para-votar-por-presidente 